\title{
Electrical Conductivity of Carbon Electrodes by Mixing Carbon Rod and Electrolyte Paste of Spent Battery
}

\author{
Suka Handaja a,b,*, Heru Susanto ${ }^{\mathrm{c}^{* *}}$, Hermawan d,*** \\ ${ }^{a}$ Environmental Science Doctoral Program, School of Postgraduate Studies, Diponegoro University, Semarang, 50241, Central Java, \\ Indonesia
}

${ }^{b}$ Instrumentation Engineering Department, Polytechnic Energy and Minerals Akamigas, Cepu-Blora 58311, Central Java, Indonesia

${ }^{c}$ Chemical Engineering Department, Diponegoro University, Semarang, 50275, Central Java, Indonesia

${ }^{d}$ Electrical Engineering Department, Diponegoro University, Semarang, 50275, Central Java, Indonesia.

\begin{abstract}
As a consequence of increasing battery use, spent batteries are increasingly contributing to solid waste. This situation has the potential to create a severe environmental problem. Thus, the utilization of these spent batteries, including the reuse of some components, is essential. The reusable components of the spent battery are carbon rods and electrolyte pastes. In this work, these components were utilized to prepare a carbon-based electrode for reverse electrodialysis. These electrodes can be an alternative to commercial Ti-based electrodes. The important characteristics of an electrode are the electrical conductivity, porosity, and surface area of the particles. This study aimed to determine the best electrical conductivity exhibited by various mixtures of carbon rods and electrolyte paste taken from spent batteries. The spent battery contained $95 \%$ carbon, and the electrolyte paste of the spent battery contained $64 \%$ carbon, 19\% zinc, and 5\% manganese. Before mixing, the carbon rods were powdered using ball mills for $4 \mathrm{~h}$; $85.6 \%$ of particles were sized $<1 \mu \mathrm{m}$. The best electrical conductivity was obtained from a mixture of carbon rods and electrolyte paste in the weight ratio of 7:2, with electrical conductivity, porosity, and surface area of $2.75 \mathrm{~S} / \mathrm{cm}, 0.019 \mathrm{cc} / \mathrm{g}$, and $15.936 \mathrm{~m} / \mathrm{g}$, respectively.
\end{abstract}

Keywords: Spent Battery, Battery Waste, Electrical Conductivity, Carbon Rods, Electrode, Electrolyte Paste

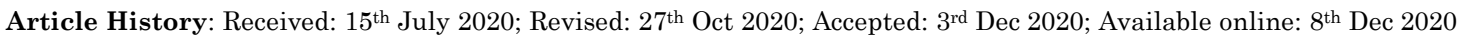

How to Cite this Article: Handaja, S., Susanto, H., and Hermawan. (2021) Electrical Conductivity of Carbon Electrodes by Mixing Carbon Rod and Electrolyte Paste of Spent Battery. Int. Journal of Renewable Energy Development, 10(2), 221-227

https://doi.org/10.14710/ijred.2021.31637

\section{Introduction}

Electrical conductivity is the ability of a material to conduct electrical current-an important characteristic considered during electrode material selection (Xingtao, et al., 2018). High electrical conductivity implies that the material will deliver the electric current easily. The electrical conductivity of an electrode is influenced by the surface area of the electrode particles; the interaction of ions and electrode particles in redox is increased in an electrode with a large surface area. As a result, it increases the number of electrons flowed by electrodes or increases the electric current (González, et al., 2011).

One method to increase the electrical conductivity is increasing the surface area of the electrode particles by making the particles small (nano/microparticles); the rearrangement of these particles results in a larger surface area (Xingtao, et al., 2018). Conductivity is also influenced by porosity, which influences the extent to which ions can enter between particles (Inoue \& Kawase, 2017).
Electrodes are commonly utilized during electrolysis (Choi, 2010). Reverse electrodialysis (RED) - a method for producing renewable energy by capturing salinity gradient energy-also requires electrodes for power generation (Susanto, et al., 2017). The electrode converts the ion flow into a flow of electrons. Studies on RED for power generation used electrodes made of Ti-based materials, which are expensive (Veerman, et al., 2010).

Carbon electrodes may be an alternative to Ti-based ones. Carbon electrodes are widely used in electrolysis because they are not easily soluble. Therefore, carbon electrodes are more durable, have good conductive properties, and are less expensive owing to the abundance of carbon in nature (Frackowiak \& Beguin, 2001).

The global primary battery production is increasing at $6 \%$ per year (Buchmann, 2020); for example, 3.88 billion units were produced in Japan in 2019 (Senzai, 2019) and 88,000 tons in Europe in 2018 (Eurostat, 2020). Resultantly, the number of spent batteries in solid waste is continuously growing. This solid waste must be managed as it can create serious environmental problems.

\footnotetext{
*Corresponding Author : * suka.budi@esdm.go.id/

** heru.susanto@che.undip.ac.id/

$* * *$ hermawan.60@gmail.com/
} 
The components of spent batteries that can be reused are carbon rods and electrolyte paste, which are utilized as electrodes in purifying water, processing waste, supercapacitors in energy storage, or reverse electrodialysis power generation (Shabeebaa, et al., 2018).

This article describes the fabrication and characterization of a carbon electrode made of a mixture of carbon rods and electrolyte paste obtained from spent batteries. Carbon rods are electrodes of batteries can contain carbon elements and electrolyte paste. In addition, manganese and zinc are present in the electrolyte paste (Haque Khan \& Kurny, 2012), increasing the conductivity of carbon electrodes. For this reason, in this study, manganese and zinc in the electrolyte paste were preserved in the carbon rod powder. This strategy can help manage the environment better, considering that spent batteries a hazardous electronic waste.

This research aimed to characterize the spent batteries and reuse the carbon rods and electrolyte paste contained within to prepare carbon electrodes. The formulation of these two components was investigated. The resulting carbon electrode was then characterized in terms of electrical conductivity.

\section{Materials and Experiment Methods}

\subsection{Materials}

As a sample material, spent batteries were taken from landfill disposal, and new batteries were obtained from the store for comparison. The binder materials were polyvinylidene difluoride (PVdF) purchased from Aldrich Merck Germany, and a solution of 1-methyl-2-pyrrolidone (NMP) purchased from Merck Germany with purity $>99.5$ $\%$. PVdF and NMP were used as binder components for the electrode particles to form electrode structures while maintaining their porous structure.

\subsection{Equipment}

The Planetary Ball Mill (Resch PM 400), a manual crusher with 250 mesh sieves, was used to turn the samples into nanoparticle size. A pressure machine (Techiro 5 Tons) was used to press the electrode. The analyzer equipment used a scale for weighing materials and samples, PSA (Particle Size Analyzer, Labtron LLPA C10) for measuring particles, SEM-EDX and XRD (Scanning Electron Microscope-Energy Dispersive X-Ray, X-Ray Diffraction) Jeol JSM Type 6510LA for morphology observation as well as composition analyzer, BET (Brunauer Emmett Teller) automated gas sorption analyzer (Quantachrome Instrument) for surface area and porosity analysis, and a multimeter for the measurement of electrical conductivity (Yokogawa CA71 Handy Cal) was used.

\subsection{Experiment Procedure}

The spent battery was obtained from waste disposal sites, and the voltage was measured at $0 \mathrm{~V}$ with a voltmeter. The spent battery was dismantled by opening the steel cover and separating the parts forming the battery. The carbon rods obtained were washed with water to eliminate any other components. After washing, the carbon rods and electrolyte paste were dried in an oven at $50{ }^{\circ} \mathrm{C}$ for $6 \mathrm{~h}$.

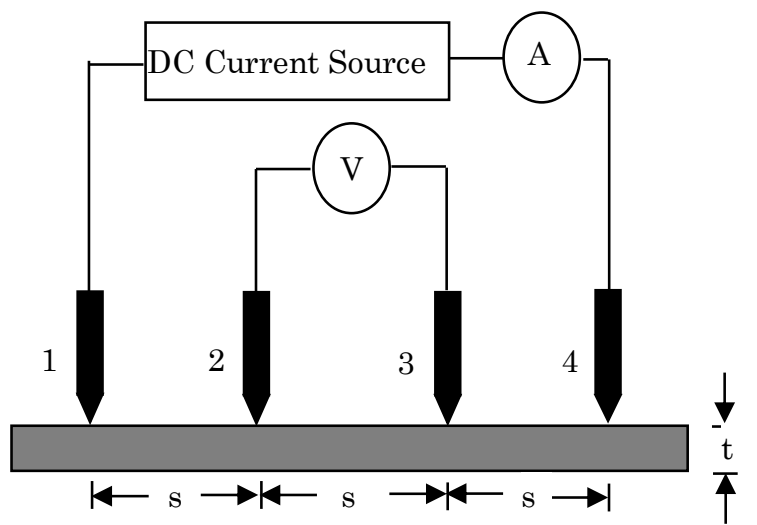

Fig. 1 The Four-Point Probe series: A is amperemeter, V is voltmeter, $\mathrm{t}$ is thickness of sample, $\mathrm{s}$ is space of probe, and $1,2,3$, 4 are the probes.

Carbon rods were prepared in nanoparticle size powder using a ball mill. Before crushing with a ball mill, the carbon rod was manually crushed and passed through 250 mesh sieve. Furthermore, the carbon rods were milled using a ball mill for $4 \mathrm{~h}$ at a maximum speed of $350 \mathrm{rpm}$; the process was stopped every $1 \mathrm{~h}$ for $10 \mathrm{~min}$. Subsequently, the particle size was measured using a particle size analyzer (PSA), and the material component was analyzed using EDX.

The powder of carbon rod particles produced from the milling process was mixed with the electrolyte paste and PVdF (by $10 \%$ of total weight) to produce carbon electrodes. The mixture was made by dissolving in NMP. The method for preparing the electrode followed the previously reported literature (Yingjie, et al., 2012). The carbon rod powder and electrolyte paste were mixed in a weight ratio of 9:0, 8:1, 7.5:1.5, and 7:2, and PVdF (10\%) was added and stirred. Then, the mixture was added to the NMP solution until a gel or slurry was obtained.

The mixture in slurry form was then cast with a thickness of $1.5 \mathrm{~mm}$ and pressed using a pressure of approximately 200 bar for $10 \mathrm{~s}$ before being stabilized by immersion in distilled water for $15 \mathrm{~min}$ (Bogeat, et al., 2014). Furthermore, the electrodes were dried in an oven at $60^{\circ} \mathrm{C}$ for $6 \mathrm{~h}$

In this work, the carbon electrodes were fabricated using 10 wt. PVdF as binders, according to previous publications. The use of PVdF of less than $5 \%$ produced a fragile mixture. However, using 5-7\% PVdF decreased the conductivity. At or above $10 \% \mathrm{PVdF}$, pore closure leads to decreasing ion movement and conductivity (Daraghmeh, et al., 2017) (Hidayat, et al., 2017). The resulting carbon electrodes were characterized by their SEM-XRD surface morphology. The surface area and porosity of the carbon electrodes were measured using BET. The electrical conductivity was measured using the four-point probe method. The four-point probe method was formulated by making four measurement points at the same distance to the sample, applying a DC source at the two outermost points, and measuring the potential difference between the two inner points, as shown in Fig. 1.

For the samples with a minimum thickness of $40 \%$ of the space probe, the resistivity value was calculated using the following equation: 


$$
\rho=\frac{V}{I} \frac{\pi \cdot t}{\ln 2}
$$

where $\rho$ is the resistivity in $\Omega$. $\mathrm{cm}$, I is the current in amperes, $\mathrm{V}$ is the voltage in volt, and $\mathrm{t}$ is the thickness of sample in $\mathrm{cm}$ (Topsoe, 1966) (Waremra \& Betaubun, 2018).

The above equation (Eq. 1) was only applied to the material with thickness $>40 \%$ of the space between the probes. Additionally, the lateral size of the material being tested must be quite large. The magnitude of the resistivity value of a material measured by the four-point probe method must be corrected for the shape and size of the sample, which is called the geometry correction factor (Topsoe, 1966). The rectangular-shaped samples with a ratio between the long edge and short edge were equal to one $(1 / \mathrm{w}=1)$, and a comparison between the short edge and space equaled $>40(\mathrm{w} / \mathrm{s}>>40$, the correction factor was $1)$. In this study, the electrodes were rectangular, with a size of $12 \mathrm{~cm} \times 12 \mathrm{~cm}$ and a thickness of $1.5 \mathrm{~mm}$. During electrical conductivity measurements, the distance between probes was kept at $2.5 \mathrm{~mm}$.

The following equation expressed the relationship between conductivity and resistivity:

$$
\sigma=\frac{1}{\rho}
$$

where $\rho$ is the resistivity in $\Omega . c m$ and $\sigma$ is the conductivity in $\mathrm{S} / \mathrm{cm}$ (Taherian, 2019).

This four-point probe method was selected because it provides precise and accurate results. Further, this method is inexpensive and simple.

\section{Results and Discussion}

\subsection{Spent Batteries and their Characteristics}

In the landfill disposal area, we found several types of primary (non-rechargeable) spent batteries used by the public. The type of the primary battery generally found were the zinc-carbon type with a diameter of $10.5 \mathrm{~mm}$ and a length of $44.5 \mathrm{~mm}$ for AAA type, a diameter of $14.5 \mathrm{~mm}$ and a length of $50.5 \mathrm{~mm}$ for AA type, and a diameter of $34.2 \mathrm{~mm}$ and a length of $61.5 \mathrm{~mm}$ for D type.
The primary battery structure consisted of a steel cover, plastic separator, cardboard paper, zinc anode, electrolyte paste, carbon electrode, upper steel cover, lower steel cover, and sealing ring (Haque Khan \& Kurny, 2012). The average weights of the new battery for AAA, $\mathrm{AA}$, and D were $8.56 \mathrm{~g}, 17.03 \mathrm{~g}$, and $92.29 \mathrm{~g}$, respectively. While, for the spent batteries, the average weights were $8.44 \mathrm{~g}, 17.64 \mathrm{~g}$, and $92.36 \mathrm{~g}$ for AAA, AA, and D types, respectively.

No significant difference in weight was observed for the new and spent batteries, indicating that the battery was packed well, so there was no material leakage. However, disposing of the spent battery in a public garbage bin without proper handling leads to the possibility of mantle corrosion being very high, causing damage to the mantle and releasing the electrolyte. In this study, no damaged spent battery was found at the final disposal site, although the spent batteries were not separated from household waste. If the spent batteries are not well-handled, the components therein will cause environmental pollution. For example, if the metal cover of the spent battery is taken by scavengers, the remaining components such as the carbon rod and electrolyte paste are thrown back into the landfill.

After dismantling, the D type component is presented in Table 1. It was observed that the largest component of battery waste was the electrolyte paste, namely $53.72 \%$ for the new battery and $58 \%$ for the spent battery. There was a decrease in the proportion of zinc anodes from $16.23 \%$ to $13.33 \%$ and an increase in the electrolyte paste proportion from $53.72 \%$ to $58 \%$. This finding indicates a chemical reaction between the zinc anode and electrolyte paste, causing some of the zinc anode to dissolve into the electrolyte paste, which leads to an increase-in the mass of the electrolyte paste spent batteries. This process is consistent with the chemical reaction of zinc-carbon batteries as follows (Linden \& Reddy, 2002):

$$
\begin{array}{llc}
\text { anode } & : & \mathrm{Zn}+2 \mathrm{Cl} \rightarrow \mathrm{ZnCl}_{2}+2 \mathrm{e} \\
\text { cathode } & : 2 \mathrm{MnO}_{2}+\mathrm{ZnCl}_{2}+\mathrm{H}_{2} \mathrm{O}+2 \mathrm{e} \rightarrow \mathrm{Mn}_{2} \mathrm{O}_{3}+\mathrm{Zn}(\mathrm{OH})_{2}+2 \mathrm{Cl} \\
\text { total } & : & \mathrm{Zn}+2 \mathrm{MnO}_{2}+\mathrm{H}_{2} \mathrm{O} \rightarrow \mathrm{Zn}(\mathrm{OH})_{2}+\mathrm{Mn}_{2} \mathrm{O}_{3}
\end{array}
$$

It can be seen from the redox reaction that the zinc anode

\begin{tabular}{|c|c|c|c|c|}
\hline \multirow{2}{*}{ Component } & \multicolumn{2}{|c|}{ New Battery } & \multicolumn{2}{|c|}{ Spent Battery } \\
\hline & Weight (gr) & $\%$ & Weight (gr) & $\%$ \\
\hline Steel Cover & 10.85 & 11.76 & 10.51 & 11.38 \\
\hline Plastic Separator & 0.73 & 0.79 & 0.74 & 0.80 \\
\hline Cardboard Paper & 5.50 & 5.96 & 4.91 & 5.32 \\
\hline Anode Zinc & 14.98 & 16.23 & 12.31 & 13.33 \\
\hline Electrolyte Paste & 49.58 & 53.72 & 53.57 & 58.00 \\
\hline Carbon Electrode & 5.56 & 6.02 & 5.43 & 5.88 \\
\hline Upper Steel Cover & 1.33 & 1.44 & 1.36 & 1.47 \\
\hline Lower Steel Cover & 1.16 & 1.26 & 1.16 & 1.26 \\
\hline Sealing Ring & 1.75 & 1.90 & 1.70 & 1.84 \\
\hline Loss & 0.85 & 0.92 & 0.67 & 0.73 \\
\hline Total & 92.29 & 100.00 & 92.35 & 100.00 \\
\hline
\end{tabular}
breaks down to $\mathrm{ZnCl}_{2}$, which will increase the mass of the electrolyte paste.

Table 1

The percentage of the weight of component new and spent $\mathrm{D}$ type battery 
Table 2

The carbon rod element of D type spent battery

\begin{tabular}{lc} 
Element & Weight (\%) \\
\hline Carbon, $\mathrm{C}$ & $\mathbf{9 5 . 3 0}$ \\
Alumina, $\mathrm{Al}_{2} \mathrm{O}_{3}$ & 0.65 \\
Silica Oxide, $\mathrm{SiO}_{2}$ & 1.85 \\
Sulfite, $\mathrm{SO}_{3}$ & 1.36 \\
Potassium Oxide, $\mathrm{K}_{2} \mathrm{O}$ & 0.10 \\
Calcium Oxide, $\mathrm{CaO}$ & 0.13 \\
Copper (II) Oxide, $\mathrm{CuO}$ & 0.60 \\
\hline
\end{tabular}

In addition to the change in weight, not all zinc anodes decayed into the electrolyte paste, so the electrolyte paste did not leak. Moreover, the zinc anode also functioned as a cover for the battery system. However, if the steel cover leaks, the zinc anode will corrode owing to contact with water and air, causing the electrolyte paste to leak through the steel cover. This condition is undesirable because the electrolyte paste will further pollute the landfill.

\subsection{Characteristics of Carbon Rod Spent Battery}

The carbon rod of the battery was used as an electrode from the battery system made from graphite. The carbon rod spent battery was characterized using EDX, and the results are shown in Table 2 . The main component of the carbon rod electrode was carbon, that is, $95.3 \%$. Impurities resulting from the graphite preparation process were also present. In addition, the impurities may also be the materials that stick when the carbon rod comes in contact with the electrolyte paste in the battery system. The carbon electrode is inert and does not react in the redox process; this can be seen in Table 1 , where the content of the carbon rod is relative between the new and spent batteries. With this high carbon content, the carbon rod of spent batteries can be reused as carbon electrodes for electrolysis processes.

The existence of impurities found in carbon rods, such as alumina and silica oxide, has to be considered, although their content is low. If the carbon rods are in an open space in the landfill and come into contact with air and water, there is a possibility that alumina and silica oxide will be released from the carbon rods. Later, it will pollute the environment by dissolving silica and alumina and eventually pollute streams and springs for the residents.

\subsection{Characteristics of Electrolyte Paste Spent Battery}

Electrolyte paste is the largest element of the battery system and a chemical material with a source of ions converted into electrical energy through a redox process on the electrodes (zinc anode and carbon rod cathode). The spent battery electrolyte paste was characterized using EDX, and the results are shown in Table 3. The carbon element was the largest, followed by the zinc, manganese, and chloride elements. The presence of metals (zinc and manganese) was almost $28 \%$, which are the element conductors. Therefore, it is reasonable to state that the addition of electrolyte paste to the carbon rod will increase the electrical conductivity.
Table 3

The electrolyte paste element of D type spent battery

\begin{tabular}{lc} 
Element & Weight (\%) \\
\hline Carbon, $\mathrm{C}$ & $\mathbf{6 4 . 0 0}$ \\
Alumina, $\mathrm{Al}_{2} \mathrm{O}_{3}$ & 0.81 \\
Chloride, $\mathrm{Cl}$ & $\mathbf{5 . 2 1}$ \\
Potassium Oxide, $\mathrm{K}_{2} \mathrm{O}$ & 0.14 \\
Manganese Oxide, $\mathrm{MnO}$ & $\mathbf{9 . 9 8}$ \\
Copper (IV) Oxide, $\mathrm{CuO}$ & 0.90 \\
Zinc Oxide, $\mathrm{ZnO}$ & $\mathbf{1 8 . 9 7}$ \\
\hline
\end{tabular}

In this study, no heavy metal elements, such as cadmium, mercury, and lead, were found as the use of these heavy metals was no longer allowed. However, owing to the function of the heavy metals as an electrolyte paste stabilizer, some manufacturers still add minimal amounts below the threshold (Haque Khan \& Kurny, 2012). As the electrolyte paste could dissolve easily in water and air, the presence of electrolyte paste-spent batteries in landfills is dangerous, especially if the battery cover is open. Chlorides, manganese oxides, and zinc oxides found in these spent batteries are soluble in water and pollute the environment through leachate channels.

Chloride was found in the electrolyte paste because the zinc-carbon battery electrolyte material is made from a mixture of manganese dioxide $\left(\mathrm{MnO}_{2}\right)$, zinc chloride $\left(\mathrm{ZnCl}_{2}\right)$, ammonium chloride $\left(\mathrm{NH}_{4} \mathrm{Cl}\right)$, water, and carbon powder (Nindhia, et al., 2016). The presence of chloride in the electrolyte paste with a relatively high content is harmful to the environment if not handled appropriately. It is known that the chloride element that mixes with water is corrosive to metals, poisonous to plants, and dangerous to human health. The chloride contained in electrolyte paste, when it is in an open space, can be a gas that will evaporate into the air and will damage the ozone layer, which eventually causes a greenhouse gas effect and is indicated as the cause of climate change.

Manganese dioxide $\left(\mathrm{MnO}_{2}\right)$ and zinc chloride $\left(\mathrm{ZnCl}_{2}\right)$ are the main ingredients of the electrolyte paste; thus, they will be found in the residual battery discharging process. The amounts of manganese oxide and zinc oxide depend on the length of the battery system discharging process. Based on the redox equation in the battery system (cf. Section 3.1), a high concentration of $\mathrm{Zn}$ and $\mathrm{Mn}$ residues will be produced if the reaction takes place perfectly. Because the samples used in this study were spent batteries from a landfill, and the voltage was measured at $0 \mathrm{~V}$, the amounts of manganese oxide and zinc oxide were significant (see Table 3).

In summary, the spent battery waste must be handled appropriately, as it has to be separated from household waste. This waste should be collected separately and should not be disposed in landfill areas. Therefore, an action to communicate the danger of spent batteries must be carried out, encouraging people to not carelessly throw them away.

\subsection{Carbon Rods Powder Distribution}

Carbon rods have to be made in nanoparticle size before they are used for the electrode. Thus, the carbon rods were crushed using a ball mill and measured by the particle size using PSA. The results are presented in Table 4. 
Table 4

The distribution of carbon rod spent battery particle size after milling

\begin{tabular}{lccc}
\hline \multicolumn{1}{c}{$\begin{array}{c}\text { Duration of } \\
\text { Milling }\end{array}$} & \multicolumn{3}{c}{$\begin{array}{c}\text { Distribution Percentage of Particle } \\
\text { Size }\end{array}$} \\
\cline { 2 - 4 } & $<\mathbf{3 2 5} \mathbf{~ n m}$ & $\begin{array}{c}\mathbf{3 2 5} \mathbf{~ n m} \\
<>\mathbf{1 0 0 0} \mathbf{~ n m}\end{array}$ & $>\mathbf{1 0 0 0} \mathbf{~ n m}$ \\
\hline 1 hour & 0 & 84.1 & 15.9 \\
2 hours & 1.2 & 83.7 & 15.1 \\
4 hours & 1.6 & 83.9 & 14.5 \\
\hline
\end{tabular}

No significant difference in particle size resulted in different milling times. Using the equipment used in this research, we could not obtain nanoparticles $<100 \mathrm{~nm}$. It is important to mention that in addition to the length of time milling, the particle size distribution was affected by the speed, diameter of the ball, and the weight of the ball to obtain finer and smaller particles.

\subsection{Carbon Electrodes XRD Analysis}

The carbon electrode pattern from a mixture of carbon rods and electrolyte paste was analyzed using XRD. The results are presented in Fig. 2. Based on the JCPDS \#751621 (Joint Committee on Powder Diffraction Standards), the carbon peaks were seen at $2 \theta$ angles of $26.22^{\circ}$ and $44.36^{\circ}$. From the pattern formed, the carbon structure formed on the electrode is amorphous and irregular. This difference in shape is due to carbon particles forming through the collision or mechanical processes.

There was a peak with high intensity indicating $\mathrm{Zn}$ and Mn materials bound to carbon. These are believed to originate from $\mathrm{Zn}$ and $\mathrm{Mn}$, which are at the $2 \theta$ angle of $33.27^{\circ}$ and $36.18^{\circ}$. Fig. 2a shows an XRD pattern for a mixture ratio of 9:0, indicating the presence of carbon rods only. It appears that carbon dominates the content of the mixture, which is in agreement with the results presented in Table 2. The peaks of $\mathrm{Mn}$ and $\mathrm{Zn}$ are seen at $2 \theta$ angles of $29.31^{\circ}$ and $33.27^{\circ}$ in Fig. $2 b$, which is a mixture with a ratio of $8: 1$. The peaks of $\mathrm{Mn}$ and $\mathrm{Zn}$ are also seen at $2 \theta$ angles of $29.59^{\circ}$ and $33.47^{\circ}$ in Fig. 2c, a mixture with a ratio of $7: 2$.

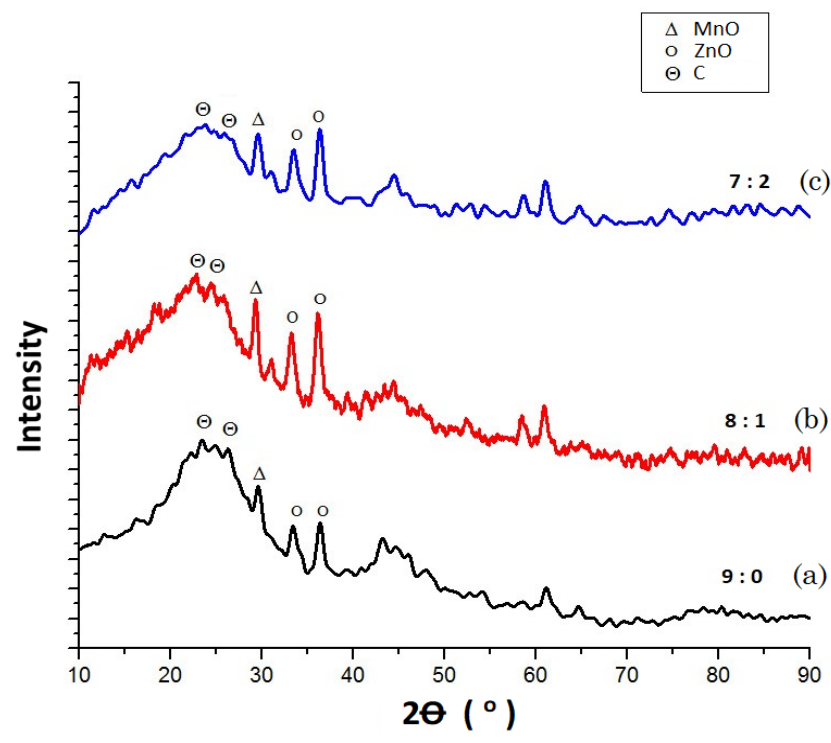

Fig. 2. XRD pattern of carbon electrodes by mixing carbon rod and electrolyte paste of spent battery with weight ratio (a) 9: 0, (b) $8: 1$, (c) $7: 2$
The three patterns in Fig. 2 show the same pattern, although they have different intensities. At an angle of approximately $26^{\circ}$, the amorphous carbon intensity of the three samples decreased because of the decreasing carbon composition. By contrast the carbon intensity with the $\mathrm{Zn}$ and Mn bonding at an angle of about $29^{\circ}$ to $36^{\circ}$ shows an increase. The XRD pattern analysis results showed that there was a slight shift from the top of the carbon, especially from the carbon that binds to $\mathrm{Zn}$ and $\mathrm{Mn}$, where the $2 \Theta$ angle shifted from $29.31^{\circ}$ to $29.59^{\circ}, 33.28^{\circ}$ to $33.48^{\circ}$ and $36.18^{\circ}$ to $36.33^{\circ}$; owing to the irregular and amorphous crystal form.

\subsection{Carbon Electrodes Morphology by SEM}

Visualization of carbon electrodes using SEM is presented in Fig. 3. The electrodes were fabricated in solid forms with a strong and hard bond to a flat surface. This flat surface structure was affected by the pressing and duration of pressing, resulting in the homogeneity of the surface and electrode structure. Fig. $3 \mathrm{a}$ and $3 \mathrm{~b}$ show the carbon rod particles and electrolyte paste before mixing. It can be seen that the electrolyte paste is softer than the carbon rod particles because the carbon rod particles have a large gap. When comparing Figs. 3c and 3d, the amount of electrolyte paste was greater in Fig. 3d. The electrolyte paste filled the gaps between the carbon rod particles.

The use of PVdF during the fabrication of the electrode was as a binder and a filler with a gap between electrode particles. The PVdF was not separated from the electrode during the immersion process using distilled water because $\mathrm{PVdF}$ is insoluble in distilled water. The gaps in the electrodes can still be maintained because of the porous structure of PVdF that can be penetrated by ions. This gap is essential for the effective flow of ions as it can penetrate the entire carbon surface, enhancing redox performance. The existence of this gap is also supported by the porosity and surface area, as shown in Table 5 .

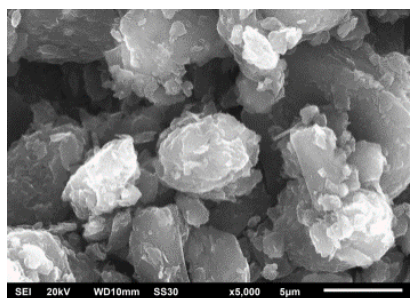

(a)

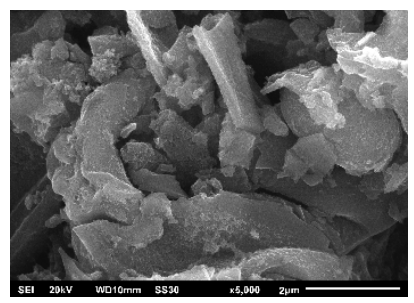

(c)

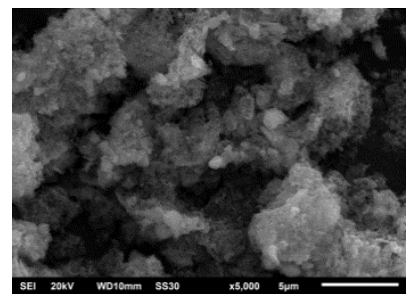

(b)

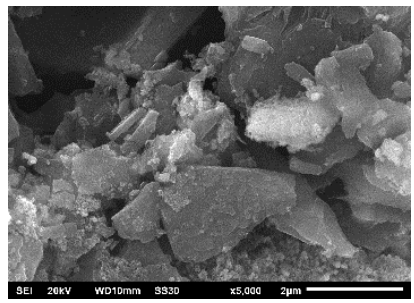

(d)
Fig. 3 Morphology of the carbon electrode by SEM: morphology of carbon rod after passing from sieved 250 mesh (a), morphology of electrolyte paste (b), morphology surface of $8: 1$ carbon electrode (c), and morphology surface of 7:2 carbon electrode(d) 
Table 5

Surface area and porosity of carbon electrodes by mixing carbon rod and electrolyte paste of spent battery

\begin{tabular}{lcc}
$\begin{array}{l}\text { Weight ratio of } \\
\text { Carbon Rod and } \\
\text { Electrolyte Paste }\end{array}$ & $\begin{array}{c}\text { Surface Area } \\
\left(\mathbf{m}^{2} / \mathbf{g}\right)\end{array}$ & $\begin{array}{c}\text { Porosity } \\
\left(\mathbf{c m}^{3} / \mathbf{g}\right)\end{array}$ \\
\hline 9:0 & 9.267 & 0.028 \\
$8: 1$ & 10.681 & 0.025 \\
$7.5: 1.5$ & 13.939 & 0.020 \\
$7: 2$ & 15.936 & 0.019 \\
\hline
\end{tabular}

\subsection{Carbon Electrodes Porosity and Surface Area}

The porosity and surface area values were obtained using BET. The results of the analysis using BET on carbon electrode samples are shown in Table 5. Table 5 shows that the addition of electrolyte paste increased surface area. These results indicate that increasing electrolyte paste increased the contact area between electrolyte ions and the electrode. It should be noted that the amount of PVdF used was the same (10\%). The emergence of the increase in surface area is caused by the replacement of carbon rod particles with electrolyte paste particles. Electrolyte paste particles that are softer than carbon rod particles increase the number of particles per unit volume, increasing the surface area. On the other hand, an increase in the number of particles per unit volume will decrease porosity (see Table 5). The presence of porosity is needed as a space for ions to flow in contact with the electrode particles. It is also expected that a large surface area will provide a more effective conversion of ions into electrons on the electrodes (Portet, et al., 2008). For this reason, further studies on the effectiveness of the electrodes in the electrolysis process need to be conducted.

\subsection{Carbon Electrodes Electrical Conductivity}

Table 6 shows the results of electrical conductivity measurements of the carbon electrodes. The electrical conductivity tended to increase with increasing concentration of the electrolyte paste, meaning that the addition of electrolyte paste causes the electrode space to be penetrated easily by ions. The reason for this phenomenon is that the added electrolyte paste contained conductive components such as manganese and zinc. The presence of these conductive components increased the electrical conductivity of the electrode. The increase in electrical conductivity has also been reported in previous studies, namely the increase in electrical conductivity due to the addition of $\mathrm{Mn}$ during the preparation of superconductors (Al Baroroh, et al., 2017). The electrical conductivity of graphite material pressurized at $1.210^{3}$ $\mathrm{N} / \mathrm{m}^{2}-101.810^{3} \mathrm{~N} / \mathrm{m}^{2}$ was in the range of $0.06 \mathrm{~S} / \mathrm{cm}-2.5$ $\mathrm{S} / \mathrm{cm}$ (Vilar, et al., 1998). The results obtained in this work showed better electrical conductivity values, with the highest electrical conductivity of $2.753 \mathrm{~S} / \mathrm{cm}$ (obtained from the mixture with a weight ratio of $7: 2$, see Table 6). In addition to the conductive component content, the electrical conductivity of the electrode is influenced by the particle size, gap, and surface area of the electrode particles.

In this article, it can be stated that the electrical value can be caused by the small particle size of the carbon increasing the number of particles per volume unit, leading to an increase in both the surface area and permeability of the ions or electrons flow. Second, the application of pressure during preparation of the electrode can also increase the number of particles per unit volume, which will impact the surface area and ion permeability. Third, the number of conductors or electrolyte materials added will increase the number of metals that could increase the electrical conductivity. Nevertheless, the conductor material should have an electrical conductivity higher than that of a carbon rod. As previously explained, the electrolyte paste contains $\mathrm{Zn}$ and $\mathrm{Mn}$; if the amount of $\mathrm{Zn}$ and $\mathrm{Mn}$ in the electrode increases, the electrical conductivity also increases. Moreover, as described in subsection 3.1, the redox reaction takes place perfectly, resulting in a high concentration of $\mathrm{Zn}$ and $\mathrm{Mn}$ produced; thus, the $\mathrm{Zn}$ and $\mathrm{Mn}$ contents in the electrolyte paste are also high. Consequently, the electrical conductivity of the carbon electrode increased.

A critical aspect of applying carbon electrodes made from a mixture of carbon rods and electrolyte paste will be applied in reverse electrodialysis power generation. It is necessary to consider the presence of $\mathrm{Zn}$ and $\mathrm{Mn}$ on the carbon electrodes. $\mathrm{Zn}$ and $\mathrm{Mn}$ should not leach or dissolve during reverse electrodialysis power generation; this may be achieved by observing the use of electrolyte solutions and switching electrode electric poles.

Table 6

Electrical conductivity of carbon electrode by mixingcarbon and electrolyte paste of spent battery

\begin{tabular}{|c|c|c|c|c|c|}
\hline $\begin{array}{l}\text { Weight Ratio of Carbon Rod and } \\
\text { Electrolyte Paste }\end{array}$ & $\begin{array}{c}\mathrm{t} \\
(\mathrm{cm})\end{array}$ & $\begin{array}{c}\mathrm{I} \\
(\mathrm{mA})\end{array}$ & $\underset{(m V o l t)}{\mathrm{V}}$ & $\begin{array}{l}\text { Resistivity } \\
\quad(\Omega . c m)\end{array}$ & $\begin{array}{c}\text { Electrical } \\
\text { Conductivity } \\
\text { (S/cm) }\end{array}$ \\
\hline \multirow[t]{3}{*}{ 9:0 } & 0.15 & 0.50 & 106.81 & 1.4516 & 0.6889 \\
\hline & & 0.55 & 118.96 & 1.4697 & 0.6804 \\
\hline & & 0.60 & 129.39 & 1.4654 & 0.6824 \\
\hline \multirow[t]{3}{*}{$8: 1$} & 0.16 & 0.50 & 36.51 & 0.5291 & 1.8897 \\
\hline & & 0.55 & 40.02 & 0.5299 & 1.8872 \\
\hline & & 0.60 & 43.86 & 0.5299 & 1.8872 \\
\hline \multirow[t]{3}{*}{$7.5: 1.5$} & 0.15 & 0.50 & 29.62 & 0.4026 & 2.4838 \\
\hline & & 0.55 & 32.52 & 0.4018 & 2.4889 \\
\hline & & 0.60 & 35.54 & 0.4026 & 2.4841 \\
\hline \multirow[t]{3}{*}{$7: 2$} & 0.14 & 0.50 & 28.67 & 0.3636 & 2.7501 \\
\hline & & 0.55 & 31.50 & 0.3632 & 2.7533 \\
\hline & & 0.60 & 34.36 & 0.3631 & 2.7535 \\
\hline
\end{tabular}




\section{Conclusion}

Spent batteries have to be appropriately managed because they contain materials that can pollute the environment, including carbon, manganese, and zinc. In this research, some materials in spent batteries were utilized for the preparation of the carbon electrode. The raw material of the carbon electrodes was powdered to nanoparticle size to obtain a large surface area for facilitating electrons flow or conductivity. The addition of spent battery electrolyte paste also contributed to the increase in electrical conductivity. Furthermore, the highest value of electrical conductivity was obtained by mixing the carbon rod powder and electrolyte paste with a weight ratio of 7:2 with an electrical conductivity of 2.75 .

\section{Acknowledgements}

We would like to express our appreciation to the Ministry of Education and Culture Republic of Indonesia for the funding of this research (via WCR project) and Laboratorium Terpadu Diponegoro University for laboratory support for BET, SEM, EDX, XRD analysis, and Laboratorium Energi of Polytechnic of Energy and Minerals Akamigas for laboratory support for electrical conductivity measurement.

\section{References}

Al Baroroh, L. A., Handayani, I. \& Rosi, M., (2017). Effects Of $\mathrm{Mn}^{7+}$ Insertion on The Conductivity and Capacitance of Nanoporous Carbon From Coconut Shell. e-Proceeding of Engineering , 4(1), 605-611; ISSN : 2355-9365.

Bogeat, A.B, Franco, M.A, Gonzalez, C.F, Garcı, A.M, \& Serrano, V.G, (2014). Electrical conductivity of activated carbonmetal oxide nanocomposites under compression : a comparison study. Phys. Chem. Chem. Phys, 16, 2516125175; DOI: 10.1039/c4cp03952a.

Buchmann, I., (2020). Battery University. [Online] Available at: https://batteryuniversity.com/learn/archive/battery_statisti cs [Accessed 23 November 2020].

Choi, J., (2010). Fabrication of a carbon electrode using activated carbon powder and application to the capacitive deionization process. Separation and Purification Technology 70, 362-366; DOI: 10.1016/j.seppur.2009.10.023

Daraghmeh, A., Hussain, S., Saadeddin, I., Servera, L., Xuriguera, E., Cornet, A., \& Cirera, A., (2017). A Study of Carbon Nanofibers and Active Carbon as Symmetric Supercapacitor in Aqueous Electrolyte: A Comparative Study. Nanoscale Research Letters, 12, 639-648; DOI: 10.1186/s11671-017-2415-z.

Eurostat, (2020). Eurostat Statistic Explained. [Online] Available at: https://ec.europa.eu/eurostat/statisticsexplained/index.php? stable $=0 \&$ title $=$ Waste_statistics__recycling_of_batteries_and_accumulators\#Sales_and_coll ection_of_portable_batteries_and_accumulators[Accessed 23 November 2020].

Frackowiak, E. \& Beguin, F., (2001). Carbon materials for the electrochemical storage of energy in capacitors. Carbon, 39, 937-950; DOI: doi.org/10.1016/S0008-6223(00)00183-4

González, J., Stoeckli, F. \& Centeno, T., (2011). The role of the electric conductivity of carbons in the electrochemical capacitor performance. Journal of Electroanalytical
Chemistry, $\quad 657, \quad 176-180$ doi.org/10.1016/j.jelechem.2011.03.025

Haque Khan, M. \& Kurny, A., (2012). Characterization of Spent Household Zinc-Carbon Dry Cell Batteries in the Process of Recovery of Value Metals. Journal of Minerals \& Materials Characterization \& Engineering, 11(66), 641-651; DOI: 10.4236/jmmce.2012.116047

Hidayat, S., Putra, R., Alamsyah, W., Saat, A.H., \& Riveli, N. (2017). Pengaruh Penambahan Karbon dan PVdF terhadap Konduktivitas Listrik Bahan Komposit LiFePO4. Prosiding Pertemuan Ilmiah XXXI HFI Jateng \& DIY, 81-84; ISSN : 0853-0823

Inoue, G. \& Kawase, M., (2017). Numerical and experimental evaluation of the relationship between porous electrode structure and effective conductivity of ions and electrons in lithium-ion batteries. Journal of Power Sources, 342, 476488; DOI :dx.doi.org/10.1016/j.jpowsour.2016.12.098.

Linden, D. \& Reddy, T. B., (2002). "8" Handbook of batteries. s.l.:McGraw-Hill, ISBN 978-0-07-135978-8..

Nindhia, T. G. T., Surata, I. W., Swastika, I. D. P. \& Wahyudi, I. M., (2016). Reuse of Carbon Paste from Used Zinc-Carbon Battery for Biogas Desulfurizer with Clay as a Binder. International Journal of Environmental Science and Development, 7, 203-206; DOI: 10.7763/IJESD.2016.V7.768.

Portet, C., Yushin, G. \& Gogotsi, Y., (2008). Effect of Carbon Particle Size on Electrochemical Performance of EDLC. Journal of The Electrochemical Society, 155(7), A531-A536; DOI: $10.1149 / 1.2918304$.

Senzai, Y., (2019). Battery Association of Japan. [Online] Available at: http://www.baj.or.jp/e/statistics/01.html [Accessed 23 November 2020].

Shabeebaa, P., Thayyil, M. S., Pillai, M. P., Soufeena, P. P., \& Niveditha, C. V. (2018). Electrochemical Investigation of Activated Carbon Electrode Supercapacitors. Russian Journal of Electrochemistry, 54(3), 302-308; ISSN 10231935

Susanto, H., Fitrianingtyas, M., Samsudin, A. M. \& Syakur, A., (2017). Experimental study of the natural organic matters effect on the power generation of reverse electrodialysis. International Journal of Energy Research, 41(10), 14741486; DOI: 10.1002/er.3728.

Taherian, R., (2019). The Theory of Electrical Conductivity. In: Electrical Conductivity in Polymer-Based Composites: Experiments, Modelling and Applications. s.l.:Elsevier Inc, 1-18; DOI: doi.org/10.1016/B978-0-12-812541-0.00001-X.

Topsoe, H., (1966). Geometric Factor of Four Point Resistivity Measurement, Vedbaek: Semiconductor Division.

Veerman, J., Saakes, M., Metz, S. \& Harmsen, G. J., (2010). Electrical Power from Sea and River Water by Reverse Electrodialysis: A First Step from the Laboratory to a Real Power Plant. Environ. Sci. Technol, 44, 9207-9212; DOI : doi.org/10.1021/es1009345

Vilar, E., de Fretias, N., de Lirio, F. \& de Sousa, F., (1998). Study of Electrical Conductivity of Graphite Felt Employed as A Porous Electrode. Brazilian Journal of Chemical Engineering, 15(3); DOI: dx.doi.org/10.1590/S010466321998000300007.

Waremra, R. S. \& Betaubun, P., (2018). Analysis of Electrical Properties Using the four point Probe Method. E3S Web of Conferences 73, ICENIS 2018, DOI doi.org/10.1051/e3sconf/20187313019.

Xingtao, X., Junfeng, L., Yuquan, L., Bing, Ni., Xinjuan, L., \& Likun, P., (2018). Selection of Carbon Electrode Materials. In: Charge and Energy Storage in Electrical Double Layers. London: Academic Press, 65-83; DOI: 10.1016/B978-0-12811370-7.00004-8

Yingjie, Z., Jia, G. \& Ting, L., (2012). Research Progress on Binder of Activated Carbon Electrode. Advanced Materials Research, 549, 780-784, ISSN: 1662-8985; DOI : 10.4028/www.scientific.net/AMR.549.780. 